\title{
Quality of life improvement in Latinas receiving combined substance use disorders and trauma-specific treatment: a cohort evaluation report
}

Miguel A. Cruz-Feliciano ${ }^{1 *}$, Christine Miranda-Díaz², Diana M. Fernández-Santos², Darice Orobitg-Brenes', Robert F. Hunter-Mellado ${ }^{2}$ and Ibis S. Carrión-González ${ }^{1}$

\begin{abstract}
Background: This study evaluates the benefits of integrating behavioral health and trauma services for Latinas with a history drug use. Changes in quality of life (QOL) domains were documented after participation in a manualized intervention in a cohort of Latinas.

Methods: Participants were part of a prospective cohort study of 136 Latinas with co-occurring disorders (COD) who may have experienced trauma and receiving services in our outpatient treatment facility in Bayamón, Puerto Rico. The WHOQOL-BREF Spanish version was used to score physical, psychological, social, and environmental QOL domains, at intake and after six months. Sociodemographic variables, alcohol, drug use, mental health disorders, and severity of substance use disorders (as defined by the DSM-5) were also tabulated. Descriptive statistics and paired $t$ test or the Wilcoxon signed-rank test were computed for comparison.

Results: A median age of 39 years was seen and with $76 \%$ high school education or higher degree. The majority were unemployed (95.9\%). A diagnosis of severe cocaine use (51.4\%) was present and almost half (49.5\%) had three or more DSM-5 diagnoses. Mean QOL scores were higher at six months with statistically significant differences in each domain. Women with neurodevelopmental disorders and schizophrenia yielded higher mean QOL scores for each domain at six months except for the social domain. Women with polydrug use and women who reported exposure to trauma and depressive disorder experienced statistically significant increments in the physical, psychological and social domains in comparison to counterpart women.
\end{abstract}

Conclusions: Significant and positive changes in $\mathrm{QOL}$ were found in each domain. Latinas who reported traumatic events had lower scores in the physical and psychological QOL domains. There was a high prevalence of diminished physical and mental functioning in Latinas with COD. The exposure to trauma and the lack of social support negatively affect treatment access and retention for Latinas.

Keywords: Quality of life, Women, Substance use disorders, Latinas

\footnotetext{
* Correspondence: miguel.cruz@uccaribe.edu

${ }^{1}$ Institute of Research, Education and Services in Addiction, Universidad

Central del Caribe School of Medicine, PO Box 60327, Bayamon, PR

00960-6032, Puerto Rico

Full list of author information is available at the end of the article
} 


\section{Background}

Behavioral health, including mental health, is a major concern. As of 2014, an estimated of 21.5 million persons aged 12 or older had substance use disorders (SUDs) and about $1.0 \%$ of the adult population had cooccurring disorders (COD) [1]. The quality of life (QOL) is a significant indicator of wellness among individuals and has been studied as a relevant clinical construct in the provision of care for substance use, and recovery services. The negative effects of SUDs in the multiple domains of QOL have been documented [2-7]. In addition, co-occurring mental health disorders and sociodemographic factors including gender, age, and educational attainment are mediating variables which influence QOL in individuals with substance use disorders (SUD) $[5,8,9]$. Published studies suggest that women in treatment for alcohol use disorder with co-occurring depression had lower QOL than women without depressive symptoms [10-13]. Gender disparities may exist in women who engage in SUD treatment services in terms of quality of health status, social context, and environmental conditions (e.g., housing, safety, and security) in the US [14]. In Puerto Rico, greater disparities in treatment provision and access to services were found in women with SUD seeking services as compared to men [15]. The literature suggests that Puerto Rican women with SUD tend to report a lower perception of wellbeing, higher prevalence of chronic diseases, depression symptoms, and lower social support than women with SUD in the US [15]. For women with SUD in the US, lower scores in the environmental QOL over time and a decrease in the social QOL score one month after treatment have been reported [14]. Other authors have presented data suggesting that recent alcohol or drug use, being in treatment, and the number of sessions attended were not significantly associated with improvements in QOL among women with SUD [14].

SUD and exposure to trauma-related events have been shown to negatively influence treatment outcomes $[16$, 17]. Women with SUD seeking substance use treatment have greater psychological distress, mental health problems, and have experienced traumatic events including sexual and physical assault as compared to men [18-25]. Trauma has been significantly correlated with physical and psychological QOL domains in previous studies but is not well understood in Latinas [14, 26, 27]. A recent study found an association between depression, substance use, and being a victim of sexual abuse during childhood and adulthood in Latinas [28]. Other studies have shown that women who use substances are significantly more likely to experience intimate partner violence (IPV) which is associated with increased drug and alcohol use [29-37], making substance use both a risk factor for and a consequence of IPV. The development of posttraumatic stress disorders (PTSD) and related symptoms that result from exposure to trauma should be examined as a factor that negatively affects treatment outcomes in populations with SUD and co-occurring depression [17].

Successful recovery from SUD has been associated with how individuals appraise and cope with stressful life events. Studies indicate that there is an association between higher perceived social support and better quality of life in the populations with SUD [38]. Women with SUD tend to perceive less social support than men, which has been shown to negatively affect treatment access and retention [39]. Moreover, higher levels of social support were predictors of higher levels in all QOL domains $[38,40]$. Previous researchers have stressed the need of integrated treatment models that address SUD, QOL, and trauma in women $[16,41,42]$. In Puerto Rico, treatment services for women with substance use disorders and trauma have been offered in a fragmented manner. The literature indicates that gender-specific, culturally responsive, comprehensive services may improve retention and outcomes for Latinas [43]. Proyecto Mujer (Project Woman) is an integrated trauma and substance use treatment service for Latinas with COD and who are at risk for HIV/AIDS and hepatitis infection. Proyecto Mujer is framed in the motivational interviewing (MI) and the transtheoretical model of change (TMC) and includes core components of Seeking Safety (SS) [44], and RESPECT (Intervention developed by Kamb et al. under the Project RESPECT study) [45, 46] evidence-based practices (EBPs). The MI and TMC approaches were incorporated to improve women's outcomes. SS focuses on safety from substance use and IPV as its main clinical area whereas Project RESPECT Enhanced Counseling was included to reduce HIV risk behaviors commonly observed in populations with SUDs.

This study aims to evaluate the benefits of an integrated behavioral health and trauma-specific services for Latinas with substance use disorders and mental illness. We describe changes in each QOL domain after enrollment in Proyecto Mujer as compared to six months later. We also identify the mediating role of sociodemographic variables and DSM-5 diagnosis criteria [47] as correlates of QOL in Latinas with COD.

\section{Methods}

\section{Setting and procedures}

Participants were part of a prospective cohort study of 136 Latinas with co-occurring disorders (COD) who may have experienced trauma and receiving services in our outpatient treatment facility in Bayamón, Puerto Rico. After the initial screening, participants signed an informed consent. Face-to-face interviews were conducted at intake and six months from January 2014 to 
September 2015. All interviews were conducted by trained case management specialists and the clinical assessment was performed by a licensed clinical psychologist. The intake and follow-up interview, as well as the clinical assessment time duration, were approximately $1 \mathrm{~h}$ each. Strictly voluntary urine test for the identification of psychoactive substances, OraQuick Advance HIV-1/2 Antibody test and counseling, and Hepatitis B and $\mathrm{C}$ test were offered to the study's participants. Positive test results were sent to the laboratory for confirmation and for treatment referral. Participants received $\$ 20.00$ incentive for the follow-up assessment completion. The study was reviewed and approved by the Universidad Central del Caribe Institutional Review Board (IRB\# 2013-24).

\section{Participants}

A total of 136 women receiving services at the clinic during the period of 14 months represented the sample of this investigation. The power of the sample was determined to be robust for statistical significance for the majority of the groups investigated. The power of the sample size for each domain is presented in Table 3 . Follow-up measure was conducted at 6 months and was completed by 107 women; representing a $79 \%$ retention rate. Eligible participants were (a) women with SUD and/or COD who are living with HIV or at risk for HIV at the time of intake, (b) between 18-64 years of age, (c) with positive 9-panel drug test or visible fresh needle tracks, (d) living in the metropolitan area of Puerto Rico; and (e) with limited or no health insurance coverage.

\section{Instruments and measures}

Data collected included sociodemographic information (age, educational attainment, race/ethnicity, employment status, monthly income, marital status, and health insurance), alcohol and drug use, mental health disorders, and severity of SUD (as defined by the DSM-5).

The WHOQOL-BREF Spanish version was used to measure physical, psychological, social, and environmental QOL domains scores, at intake and six months after intake. The areas of QOL represent categories of functioning within each domain. The physical domain refers to elements of activities of daily living, energy, mobility, pain, sleep, rest and work capability. The psychological domain for QOL is associated with body image, appearance, negative and positive feeling, self-esteem, memory, and concentration. The social domain describes personal relationships, social support, and sexual activity. The environmental denotes financial resources, freedom, security, safety, opportunities for recreation and leisure. The WHOQOL-BREF is a 26-item abbreviated form of the WHOQOL-100 developed by the World Health Organization [48]. The WHOQOL-BREF guidelines were followed to calculate raw domain scores and transform them to the $0-100$ scale [48]. Normative means scores for each QOL domain were calculated for the general population by other investigators [49, 50]. For the purposes of our study, we have used the following normative mean scores as comparison: 75.1 $(\mathrm{SD}=13) / 74(\mathrm{SD}=16)$ for the environmental domain, $73.5(\mathrm{SD}=18.1) / 77 \quad(\mathrm{SD}=17)$ for the physical domain, $69(\mathrm{SD}=18) / 71.5(\mathrm{SD}=18.2)$ for the social domain, and $69(\mathrm{SD}=16) / 70.6(\mathrm{SD}=14)$ for the psychological domain $[49,50]$.

\section{Treatment intervention}

Proyecto Mujer treatment intervention consists of 11 sessions delivered within 6 months that includes core components of two EPBs; however, treatment in some instances was completed in an 8-months period. The average number of sessions completed was three; delivered in an individual format (See Fig. 1). SS is a widely used EBP that addresses cognitive, behavioral, interpersonal, and case management issues in the integrated treatment of post-traumatic stress disorder (PTSD) and substance use [51-55]. SS is designed to be flexible in order to adapt to the client's needs, clinician's preferences, and a variety of topics [44]. The RESPECT Enhanced Counseling is an EBP that has been shown to provide good evidence to change HIV/STD risk behaviors [45]. RESPECT Enhanced Counseling is a one-onone client focused HIV/STD prevention intervention that includes four interactive sessions. This EBP also helps participants build a short and long-term HIV risk reduction plan.

SS and RESPECT Enhanced Counseling sessions were alternated and combined starting with the first SS treatment topic ("Introduction to treatment" / Case management) and the first RESPECT Enhanced Counseling session ("HIV personal risk factors and barriers to risk reduction"/Counseling) to engage participants early in treatment. Proyecto Mujer includes five SS treatment

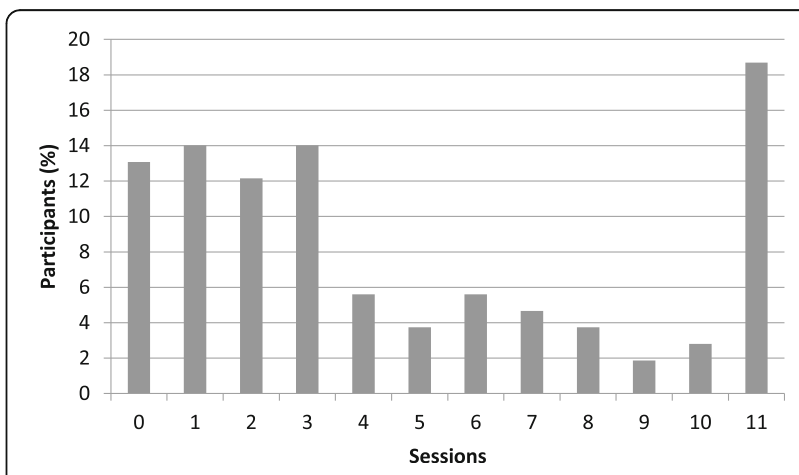

Fig. 1 Distribution of session completed by participants ( $n=107)$. Note. Average number of sessions completed by each participant 
topics: Safety (combination), When Substances Control You (cognitive), Coping with Triggers (behavioral), Setting Boundaries in Relationships (interpersonal) and Getting Others to Support Your Recovery (interpersonal). These topics were selected based on the previous experiences with this population and the length of the intervention. RESPECT Enhanced Counseling focused on condom use attitudes, social norms, support for condom use, and condom use self-efficacy [56]. Proyecto Mujer was delivered by trained case managers, substance use counselors, and a licensed clinical psychologist. To enhance the fidelity of the intervention, sessions were audiotaped and discussed during clinical supervision and group discussion.

Previous research has established the effectiveness of combining $\mathrm{MI}$ and TMC in substance use disorders treatment programs [57]. Proyecto Mujer used this combined framework to support clients' motivation for change based on their stage of readiness. MI is a clinical approach applied to substance use in which the clinician enhances client motivation for change through the development of a client-centered therapeutic relationship [58]. The TMC assess patients' readiness to adopt health-promoting behaviors through five stages of change including precontemplation, contemplation, preparation, action, and maintenance [59, 60].

\section{Data analysis}

Descriptive statistics were used to summarize the characteristics of the participants of the study: frequencies and percentages for categorical variables and central tendency (mean/median) and dispersion measures (SD) for continuous variables. To account for the distribution of continuous variables in the dataset, a normality diagnostic test was performed using the Shapiro-Francia estimator. Independent variables were sociodemographic variables (age, marital status, and educational level) substance use disorders, mental health disorders (personality, bipolar, depression, and anxiety), and trauma. Variables were analyzed using a before/after approach with the ordinary paired $t$ test. The significance level $(\alpha)$ was set to $\leq 0.05$. Post-hoc power $(1-\beta)$ analyses were also conducted and reported. Statistical analyses were performed by IBM Statistical Package for Social Sciences v.20.0 for Windows [61] and G*Power 3.1.3 [62]. Women with neurodevelopmental disorders and schizophrenia $(n=23)$ were excluded from the paired $t$-test analysis due to cognitive impairment [14] and adaptation to the current treatment intervention. In this group, statistically significant differences in treatment variables at six months were not found.

\section{Results}

Table 1 shows the substance use profile, mental health screening, HIV and hepatitis clinical status at intake.
Table 1 Intake and follow-up substance use disorders, mental health disorders, and clinical variables $(n=107)$

\begin{tabular}{|c|c|c|c|c|}
\hline \multirow[t]{2}{*}{ Variable } & \multicolumn{2}{|c|}{ Intake } & \multicolumn{2}{|c|}{ Six months } \\
\hline & $\bar{n}$ & $\%$ & $n$ & $\%$ \\
\hline \multicolumn{5}{|l|}{$\overline{\text { SUD }^{a}}$} \\
\hline Alcohol & 47 & 43.9 & 31 & 29.0 \\
\hline Cocaine & 34 & 31.8 & 17 & 15.9 \\
\hline Heroin & 13 & 12.1 & 19 & 17.8 \\
\hline Cannabis & 30 & 28.0 & 5 & 4.7 \\
\hline Benzodiazepine & 19 & 17.8 & 12 & 11.2 \\
\hline Tranquilizer & 7 & 6.5 & 2 & 1.9 \\
\hline \multicolumn{5}{|c|}{ Mental Health Screening a } \\
\hline Neurodevelopment & 18 & 16.8 & - & - \\
\hline Schizophrenia & 6 & 5.6 & - & - \\
\hline Bipolar & 21 & 19.6 & - & - \\
\hline Depression & 41 & 38.3 & - & - \\
\hline Anxiety & 13 & 12.1 & - & - \\
\hline Trauma & 78 & 72.9 & - & - \\
\hline Disruptive & 11 & 10.3 & - & - \\
\hline Substance use & 99 & 92.5 & - & - \\
\hline Personality & 20 & 18.7 & - & - \\
\hline Suicidal Behavior & 8 & 7.5 & - & - \\
\hline \multicolumn{5}{|l|}{ Clinical variables ${ }^{a}$} \\
\hline $\mathrm{HIV}+$ & 16 & 15.0 & - & - \\
\hline $\mathrm{HBV}+$ & 3 & 2.8 & - & - \\
\hline $\mathrm{HCV}+$ & 11 & 10.3 & - & - \\
\hline
\end{tabular}

SUD Substance use disorders

${ }^{a}$ Non-mutually exclusive

Participants on average were 39 years old, $98 \%$ identified themselves as Latinas, 76\% completed a high school education or a higher degree, and $95.5 \%$ were unemployed. Most women (85\%) reported being single. At intake, $38.5 \%$ reported regular health status. At intake, about $73 \%$ of women reported previous exposure to traumatic events.

Table 2 shows substance use disorders as defined by DSM-5 diagnostic criteria at intake. Most women were diagnosed with severe cocaine use (51.4\%) followed by

Table 2 Substance-related DSM-5 diagnostic criteria at intake $(n=107)$

\begin{tabular}{|c|c|c|c|c|c|c|c|c|}
\hline \multirow{2}{*}{$\begin{array}{l}\text { DSM-5 } \\
\text { diagnostic criteria }^{\text {a }}\end{array}$} & \multicolumn{2}{|c|}{ No diagnosis } & \multicolumn{2}{|c|}{ Mild } & \multicolumn{2}{|c|}{ Moderate } & \multicolumn{2}{|c|}{ Severe } \\
\hline & $n$ & $\%$ & $n$ & $\%$ & $n$ & $\%$ & $n$ & $\%$ \\
\hline Alcohol & 42 & 39.3 & 12 & 11.2 & 22 & 20.6 & 31 & 29.0 \\
\hline Cocaine & 35 & 32.7 & 7 & 6.5 & 10 & 9.3 & 55 & 5 \\
\hline Cannabis & 38 & 35.5 & 17 & 15.9 & 26 & 24.3 & 26 & 24.3 \\
\hline Opioid & 74 & 69.2 & 1 & 0.9 & 4 & 3.7 & 28 & 26.2 \\
\hline
\end{tabular}

${ }^{a}$ Non-mutually exclusive 
alcohol use disorder $(29.0 \%)$ and opioid use disorder (26.2\%). Almost half (49.5\%) had three or more DSM-5 diagnoses.

Cronbach's alpha coefficient was applied to examine the internal consistency of QOL domains. We obtained a moderate to high internal consistency for each QOL domains; physical 0.736, psychological 0.792, social 0.651 , and environmental 0.811. Table 3 shows the changes in QOL by domain at intake and at six months for the sample $(n=107)$, for women without neurodevelopmental disorders and schizophrenia $(n=84)$, and for women with neurodevelopmental disorders and schizophrenia $(n=23)$. The mean QOL scores were higher at six months with statistically significant differences in each domain $(p \leq 0.05)$ : physical domain (mean difference $=-4.5$ and mean difference $=-5.0$ ), psychological domain (mean difference $=-6.3$ and mean difference $=-6.2$ ), social domain (mean difference $=-6.9$ and mean difference $=-9.4$ ), and environmental domain (mean difference $=-4.8$ and mean difference $=-6.1$ ) for all women in the sample and for women without neurodevelopmental disorders and schizophrenia. For women with neurodevelopmental disorders and schizophrenia, the mean QOL scores for each domain were higher at six months except for the social domain: physical domain (mean difference $=-2.2$ ), psychological domain (mean difference $=-6.0$ ), social domain (mean difference $=2.2$ ),

Table 3 QOL mean scores at intake and follow-up for different populations

\begin{tabular}{|c|c|c|c|c|c|}
\hline \multirow[t]{2}{*}{ QOL Domain } & Intake & Six months & $p$-value ${ }^{a}$ & $E S \wedge^{b}$ & $1-\beta^{c}$ \\
\hline & Mean (SD) & \multicolumn{4}{|l|}{ Mean (SD) } \\
\hline \multicolumn{6}{|c|}{ All women $(n=107)$} \\
\hline Physical & $57.3(19.8)$ & $61.8(20.7)$ & 0.015 & 0.239 & 0.69 \\
\hline Psychological & $59.9(20.8)$ & $66.2(21.5)$ & 0.002 & 0.313 & 0.89 \\
\hline Social & $58.9(24.1)$ & $65.8(26.4)$ & 0.008 & 0.262 & 0.77 \\
\hline Environmental & $55.8(18.9)$ & $60.6(19.7)$ & 0.009 & 0.257 & 0.75 \\
\hline \multicolumn{6}{|c|}{ Women without neurodevelopmental disorders and schizophrenia $(n=84)$} \\
\hline Physical & $58.8(19.3)$ & $63.8(19.0)$ & 0.012 & 0.280 & 0.72 \\
\hline Psychological & $61.3(20.1)$ & $67.5(21.4)$ & 0.007 & 0.302 & 0.78 \\
\hline Social & $59.4(24.2)$ & $68.8(24$ & 0.001 & 0.379 & 0.93 \\
\hline Environmental & $56.8(18.5)$ & $62.9(18.8)$ & 0.002 & 0.342 & 0.87 \\
\hline \multicolumn{6}{|c|}{ Women with neurodevelopmental disorders and schizophrenia $(n=23)$} \\
\hline Physical & $52.1(21.4)$ & $54.3(25.2)$ & 0.620 & 0.105 & 0.08 \\
\hline Psychological & $55.2(23.2)$ & $61.2(21.7)$ & 0.097 & 0.361 & 0.38 \\
\hline Social & $57.1(24.3)$ & 54.9 (31.4) & 0.734 & 0.072 & 0.06 \\
\hline Environmental & $52.0(20.1)$ & $52.1(20.8)$ & 0.977 & 0.006 & 0.05 \\
\hline
\end{tabular}

${ }^{a} p$-value from paired $t$-test analysis

${ }^{\mathrm{b}} \mathrm{ES}=\mathrm{Effect}$ size. $\mathrm{ES} \wedge$ the correlation between measures was considered in the calculation (Cohen's method)

c Power obtained from the post-hoc analysis and environmental domain (mean difference $=-0.1$ ) but did not reach statistical significance.

Changes in QOL by domain at intake and at six months by selected sociodemographic characteristics are presented in Table 4. Being single (mean difference $=-12.1)$ or married (mean difference $=-9.6)$ and higher educational attainment (mean difference $=-4.2$ ) were all associated with statistically significant increments in the physical domain score $(p \leq 0.05)$. In the psychological domain, having an education equal or less than high school yielded statistically significant differences (mean difference $=-13.8)$. Significant increments were also observed in the social domain $(p \leq 0.05)$ in young or middle-aged adult (mean difference $=-9.7$; mean difference $=-11.5$ ), never married (mean difference $=-10.0$ ), and higher educational attainment (mean difference $=-10.3$ ). In the environmental QOL domain, being middle-aged (mean difference $=-8.3$ ), never married (mean difference $=-6.7$ ), and with high or low educational attainment (mean difference $=-8.0$, mean difference $=-5.6$ ) yielded statistical significant differences.

Changes in QOL by domain by clinical variables are presented in Table 5. Polydrug use was all associated with statistically significant increments in the physical, psychological and social domains $(p \leq 0.05)$. Significant increments $(p \leq 0.05)$ in each domain among those who reported exposure to trauma and depressive disorder were also observed. Those with an anxiety disorder also experience significant increments in the social and environmental domains $(p \leq 0.05)$.

\section{Discussion}

Mean scores within QOL domains remained significantly lower in our sample as compared with mean scores for women in treatment centers in the US and the general population $[14,49,50]$. Our study confirms previous research that suggests that women with COD obtain lower mean QOL scores than men [10-13]. Similar to a study conducted in the US, women reported lower scores in the environmental domain [14]. A study found that being older was associated with low physical quality of life; however, we did not found significant increments in this domain by age [14]. We confirmed that women reporting traumatic events had lower scores in the physical and psychological QOL domains [14]. As previous research, depressive and anxiety disorders were associated with lower QOL mean scores [13].

Positive changes in QOL were found in each domain. Previous research has emphasized that participation in substance use treatment services did not predict improvements in quality of life [14]. In our study, women's readiness for change might explain this improvement. Proyecto Mujer includes an MI approach which has been shown to be an effective therapeutic tool to influence 
Table 4 Change in QOL domains by sociodemographic characteristics $(n=86)$

\begin{tabular}{|c|c|c|c|c|c|c|c|c|}
\hline & Physical & Psychological & Social & Environmental & Physical & Psychological & Social & Environmental \\
\hline & Mean (SD) & Mean (SD) & Mean (SD) & Mean (SD) & Mean (SD) & Mean (SD) & Mean (SD) & Mean (SD) \\
\hline \multicolumn{9}{|l|}{ Age } \\
\hline $18-34$ & $57.8(19.5)$ & $57.7(21.0)$ & $57.9(22.3)$ & $56.1(20.3)$ & $65.1(15.0)$ & $64.8(19.1)$ & $* 67.6$ (23.8) & $61.0(17.0)$ \\
\hline $35-55$ & $57.4(19.9)$ & $63.5(19.0)$ & $59.5(25.3)$ & $56.2(18.1)$ & $60.7(21.7)$ & $67.0(23.5)$ & *71.0 (24.8) & *62.9 (20.3) \\
\hline $56-64$ & $69.7(13.5)$ & $66.0(22.6)$ & $57.9(21.8)$ & $67.1(6.0)$ & $75.1(8.7)$ & 80.4 (11.6) & $70.6(23.8)$ & $74.3(13.3)$ \\
\hline \multicolumn{9}{|l|}{ Marital status } \\
\hline Single & $51.4(21.4)$ & $60.5(20.3)$ & $65.5(23.6)$ & $54.7(13.6)$ & *63.5 (19.7) & $69.5(20.2)$ & $73.0(24.1)$ & $59.3(16.4)$ \\
\hline Married & $59.7(18.2)$ & $58.9(20.6)$ & $69.6(26.2)$ & $60.0(21.6)$ & *69.3 (16.5) & $67.9(20.3)$ & $78.5(20.4)$ & $67.7(21.4)$ \\
\hline Never married & $60.5(18.8)$ & $62.1(20.2)$ & $54.9(23.0)$ & $56.5(19.0)$ & $62.4(19.5)$ & $66.9(22.3)$ & *64.9 (24.7) & *62.5 (18.8) \\
\hline \multicolumn{9}{|l|}{ Education } \\
\hline Less than 12 grade & $56.4(18.1)$ & $58.2(19.6)$ & $63.7(24.8)$ & $55.1(17.4)$ & $65.4(17.7)$ & *72.0 (15.6) & $69.2(25.2)$ & *63.1 (18.2) \\
\hline HS or higher & $59.3(19.6)$ & $62.0(20.2)$ & $58.4(24.1)$ & $57.2(18.9)$ & *63.5 (19.4) & $66.5(22.5)$ & $* * 68.7(24.2)$ & *62.8 (19.1) \\
\hline
\end{tabular}

$p$-value obtained from paired $t$-test. ${ }^{*} p<0.05 ;{ }^{* *} p<0.01$

clients' behavioral change [58]. Moreover, previous research has suggested that quality of the client-therapist relationship or therapeutic alliance predict treatment outcomes [63, 64]. Other non-specific factors that should be considered are the therapist's empathy and client-therapist goal consensus and collaboration which have found to support client autonomy and engagement in the therapeutic process [65]. Further research is needed to address the influence of these factors in the overall QOL in the SUD populations.

QOL has been recognized as an outcome indicator of mental health services. This study aimed to explore the benefits of integrating behavioral health and trauma services for Latinas and to describe changes in QOL in each domain after enrollment in Proyecto Mujer. Findings indicate positive changes in QOL domains over the six-month period; however, changes in QOL for persons with neurodevelopmental disorder and schizophrenia were not significant. Factors that influence QOL changes for schizophrenia patients include distress factor including severity of symptoms; coping factors such as coping styles, and social support; and personality related factors which include self-efficacy, self-esteem, and emotional distress (with negative loading) [66]. Our findings confirmed previous recommendations for planning combined substance use and trauma-specific services according to the severity of substance use disorders and the co-occurring mental health disorders.

This study has some methodological limitations. Women seeking treatment for SUDs were voluntary participants receiving treatment; generalization to women with SUDs out of treatment is not possible. Definite causal association between treatment and measures improvement cannot be established in this study. Crosscomparison with previous studies is difficult due to the lack of uniformity used to measure QOL. Most studies have measured changes in health-related quality of life rather than changes in the overall QOL which is a critical component for women using substances. The positive improvements in QOL domains yielded in this

Table 5 Change in QOL domains by type of use, history of trauma, and mental health disorders as defined by DSM-5 ( $n=86$ )

\begin{tabular}{|c|c|c|c|c|c|c|c|c|}
\hline \multirow[t]{3}{*}{ Variable } & \multicolumn{4}{|l|}{ Intake } & \multicolumn{4}{|l|}{ Six-months } \\
\hline & Physical & Psychological & Social & Environmental & Physical & Psychological & Social & Environmental \\
\hline & Mean (SD) & Mean (SD) & Mean (SD) & Mean (SD) & Mean (SD) & Mean (SD) & Mean (SD) & Mean (SD) \\
\hline \multicolumn{9}{|l|}{ Type of user } \\
\hline 1 drug & $51.4(19.5)$ & $56.1(17.2)$ & $41.1(21.5)$ & $51.3(21.5)$ & $52.9(21.6)$ & $63.8(17.7)$ & *58.6 (22.4) & *(62.9 (19.9) \\
\hline Polydrug & $61.4(19.4)$ & $63.7(20.5)$ & $64.5(22.3)$ & $59.7(17.1)$ & ${ }^{*} 67.4(17.0)$ & *69.8 (21.5) & *72.6 (23.2) & $64.1(17.4)$ \\
\hline History of trauma & 59.9 (19.3) & $63.3(20.4)$ & $59.9(21.7)$ & $59.1(18.2)$ & *64.9 (18.8) & *70.3 (20.2) & *69.4 (23.3) & *64.5 (17.0) \\
\hline Bipolar disorder & $61.7(20.4)$ & $61.7(19.0)$ & $59.1(22.0)$ & $63.9(18.8)$ & $59.5(22.6)$ & $65.7(24.6)$ & $66.3(28.3)$ & $65.2(19.6)$ \\
\hline Personality disorder & $54.7(18.5)$ & $59.1(20.6)$ & $55.0(27.3)$ & $52.6(17.3)$ & $59.4(17.9)$ & $64.3(21.3)$ & $63.5(24.9)$ & $56.7(17.7)$ \\
\hline Depressive disorder & $58.5(19.9)$ & $63.3(19.7)$ & $61.6(25.3)$ & $56.9(17.8)$ & ${ }^{*} 67.0(17.8)$ & *71.7 (20.9) & *72.3 (21.8) & *64.4 (16.6) \\
\hline Anxiety disorder & $53.8(19.7)$ & $55.8(23.9)$ & $53.6(20.1)$ & $55.7(18.7)$ & $57.0(19.2)$ & $66.8(12.3)$ & $* 72.3(18.5)$ & *63.6 (18.0) \\
\hline
\end{tabular}


study should be measured for an extended period to determine if the effects of the intervention remain.

\section{Conclusions}

Results of this study highlight the profile of Latinas with COD seeking treatment for SUDs. The exposure to trauma and the lack of social support negatively affect treatment access and retention for Latinas. Additional studies are needed to examine if Proyecto Mujer might serve to further increase the likelihood of better treatment outcomes in women with COD.

\section{Abbreviations \\ COD: Co-occurring disorders; EBPs: Evidence-based practices; IPV: Intimate partner violence; MI: Motivational interviewing; PTSD: Post-traumatic stress disorder; QOL: Quality of life; SS: Seeking safety; SUD: Substance use disorders; TMC: Transtheoretical model of change}

\section{Acknowledgements}

Not applicable.

\section{Funding}

The research reported in this article was supported by the following grants from the Substance Abuse and Mental Health Service Administration (SAMHSA): T102454, the Puerto Rico Clinical and Translational Research Consortium (PRCTRC): U54MD007587 and the Research Centers in Minority Institutions (RCMI): G12MD007583.

\section{Availability of data and materials}

The datasets used and/or analyzed during the current study available from the corresponding author on reasonable request

\section{Authors' contributions}

All the authors made a substantial contribution to the conception and the analysis and interpretation of data. MACF and CMD participated in drafting the manuscript. The second author contributed equally to the manuscript as the first author. DMFS, DOB, RFHM, and ISCG participated in revising the manuscript for important intellectual content. All the authors gave their final approval of the version submitted for publication.

\section{Competing interests}

The authors declare that they have no competing interests.

\section{Consent for publication}

Not applicable.

\section{Ethics approval and consent to participate}

The study was reviewed and approved by the Universidad Central del Caribe Institutional Review Board (IRB\# 2013-24).

\section{Publisher's Note}

Springer Nature remains neutral with regard to jurisdictional claims in published maps and institutional affiliations.

\footnotetext{
Author details

${ }^{1}$ Institute of Research, Education and Services in Addiction, Universidad Central del Caribe School of Medicine, PO Box 60327, Bayamon, PR 00960-6032, Puerto Rico. ${ }^{2}$ Internal Medicine Department, Universidad Central del Caribe School of Medicine, PO Box 60327, Bayamon, PR 00960-6032, Puerto Rico.

Received: 20 January 2017 Accepted: 25 April 2017

Published online: 02 May 2017

\section{References}

1. Center for Behavioral Health Statistics and Quality. Behavioral health trends in the United States: Results from the 2014 National Survey on Drug Use
}

and Health. 2015; HHS Publication No. SMA 15-4927, NSDUH Series H-50. Retrieved from http://www.samhsa.gov/data/.

2. Hubbard RL, Craddock SG, Anderson J. Overview of 5-year follow-up outcomes in the drug abuse treatment outcome studies (DATOS). J Subst Abuse Treat. 2003;25(3):125-34.

3. Morgan TJ, Morgenstern J, Blanchard KA, Labouvie E, Bux DA. Health-related quality of life for adults participating in outpatient substance abuse treatment. AJOA. 2003;12:198-210.

4. Préau M, Protopopescu C, Spire B, Sobel A, Dellamonica P, Moatti JP, Carrieri MP. MANIF-2000 Study Group. Health-related quality of life among both current and former injection drug users who are HIV-infected. Drug Alcohol Depend. 2007;86(2-3):175-82.

5. Smith KW, Larson MJ. Quality of life assessments by adult substance abusers receiving publicly funded treatment in Massachusetts. Am J Drug Alcohol Abuse. 2003:29(2):323-35.

6. Stein MD, Mulvey KP, Plough A, Samet JH. The functioning and well-being of persons who seek treatment for drug and alcohol use. J Subst Abuse. 1998;10(1):75-84.

7. Volk RJ, Cantor SB, Steinbauer JR, Cass AR. Alcohol use disorders, consumption patterns, and health-related quality of life of primary care patients. Alcohol Clin Exp Res. 1997:21(5):899-905.

8. Donovan D, Mattson M, Cisler R, Longabaugh R, Zweben A. Quality of life as an outcome measure in alcoholism treatment research. J Stud Alcohol Suppl. 2005;15:119-39.

9. Rudolf $\mathrm{H}$, Watts J. Quality of life in substance abuse and dependency. Int Rev Psychiatry. 2002;14(3):190-7.

10. Benaiges I, Prat G, Adan A. Health-related quality of life in patients with dual diagnosis: clinical correlates. Health Qual Life Outcomes. 2012;10:106.

11. Pasareanu AR, Opsal A, Vederhus JK, Kristensen Ø, Clausen T. Quality of life improved following in-patient substance use disorder treatment. Health Qual Life Outcomes. 2015;13:35.

12. Rudolf $H$, Priebe $S$. Subjective quality of life and depressive symptoms in women with alcoholism during detoxification treatment. Drug Alcohol Depend. 2002:66:71-6.

13. Muller AE. Many correlates of poor quality of life among substance users entering treatment are not addiction-specific. Health Qual Life Outcomes. 2016;14:39.

14. Tracy EM, Laudet AB, Min MO, Kim H, Brown S, Jun MK, Singer L. Prospective patterns and correlates of quality of life among women in substance abuse treatment. Drug Alcohol Depend. 2012;124:242-9.

15. Robles RR, Matos TD, Deren S, Colón HM, Sahai H, Marrero CA, et al. Drug treatment disparities among Hispanic drug-using women in Puerto Rico and New York City. Health Policy. 2006;75(2):159-69.

16. Laudet $A B$. The case for considering quality of life in addiction research and clinical practice. Addict Sci Clin Pract. 2011;6(1):44-55.

17. Driessen M, Schulte S, Luedecke C, Schaefer I, Sutmann F, Ohlmeier M, et al. Trauma and PTSD in patients with alcohol, drug, or dual dependence: a multi-center study. Alcohol Clin Exp Res. 2008:32:481-8.

18. Najavits LM. Seeking Safety: An evidence-based model for substance abuse and trauma/PTSD. In: Witkiewitz KA, Marlatt GA, editors. Therapist's guide to evidence-based relapse prevention: Practical resources for the mental health professional. San Diego: Elsevier Press; 2007.

19. Brady KT, Killeen T, Saladin ME, Dansky B, Becker S. Comorbid substance abuse and posttraumatic stress disorder: Characteristics of women in treatment. AJOA. 1994;3(2):160-4

20. Dansky BS, Brady KT, Saladin ME, Killeen T, Becker S, Roitzsch JC Victimization and PTSD in individuals with substance use disorders: Gender and racial differences. Am J Drug Alcohol Abuse. 1996;22(1):75-93.

21. Grella CE. From generic to gender-responsive treatment: changes in socia policies, treatment services, and outcomes of women in substance abuse treatment. J Psychoactive Drugs. 2008;5:327-43.

22. Hien DA, Cohen LR, Miele GM, Litt LC, Capstick C. Promising treatments for women with comorbid PTSD and substance use disorders. Am J Psychiatry. 2004:161(8):1426-32

23. Cohen LR, Hien DA. Treatment outcomes for women with substance abuse and PTSD who have experienced complex trauma. Psychiatr Serv. 2006; 57(1):100-6

24. Hien DA, Wells EA, Jiang $H$, Suarez-Morales $L$, Campbell AN, Cohen LR, et al. Multisite randomized trial of behavioral interventions for women with cooccurring PTSD and substance use disorders. J Consult Clin Psychol. 2009; 77(4):607-19. 
25. Miller BA, Downs WR, Testa M. Interrelationships between victimization experiences and women's alcohol use. J Stud Alcohol Suppl. 1993;11:109-17.

26. Root MPP. Treatment failures: root of sexual victimization in women's addictive behavior. Am J Orthopsychiatry. 1989;59:542-9.

27. Singer LT, Farkas K, Arendt R, Minnes S, Yamashita T, Kliegman R. Increased psychological distress in postpartum, cocaine using mothers. J Subst Abuse. 1995; 17(2):65-74.

28. Ulibarri M, Ulloa EC, Salazar M. Associations between mental health, substance use, and sexual abuse experiences among Latinas. J Child Sex Abus. 2015;24(1):35-54.

29. Cunradi CB, Caetano R, Schafer J. Alcohol-related problems, drug use, and male intimate partner violence severity among US couples. Alcohol Clin Exp Res. 2002;26(4):493-500.

30. Dansky BS, Byrne CA, Brady KT. Intimate partner violence and post-traumatic stress disorder among individuals with cocaine dependence. Am J Drug Alcohol Abuse. 1999;25:257-68

31. El-Bassel N, Gilbert L, Frye V, Wu E, Go H, Hill J, Richman BL. Physical and sexual intimate partner violence among women in methadone maintenance treatment. Psychol Addict Behav. 2004;18:180-3.

32. McKinney CM, Caetano R, Rodriguez LA, Okoro N. Does alcohol involvement increase the severity of intimate partner violence? Alcohol Clin Exp Res. 2010;34:655-8

33. El-Bassel N, Gilbert L, Wu E, Go H, Hill J. Relationship between drug abuse and intimate partner violence: A longitudinal study among women receiving methadone. Am J Public Health. 2005;95:465-70.

34. Kilpatrick DG, Acierno R, Resnick HS, Saunders BE, Best CL. A 2-year longitudinal analysis of the relationships between violent assault and substance use in women. J Consult Clin Psychol. 1997;65:834-47.

35. Testa M, Livingston JA, Hoffman JH. Does sexual victimization predict subsequent alcohol consumption? A prospective study among a community sample of women. Addict Behav. 2007;32:2926-39.

36. Testa M, Livingston JA, Leonard KE. Women's substance use and experiences of intimate partner violence: A longitudinal investigation among a community sample. Addict Behav. 2003;28:1649-64.

37. Martino SC, Collins RL, Ellickson PL. Cross-lagged relationships between substance use and intimate partner violence among a sample of young adult women. J Stud Alcohol. 2005;66(1):139-48.

38. Brown S, Jun MK, Min MO, Tracy EM. Impact of dual disorders, trauma, and social support on quality of life among women in treatment for substance dependence. J Dual Diagn. 2013;9(1):61-71.

39. Greenfield SF, Brooks AJ, Gordon SM, Green CA, Kropp F, McHugha RK, Lincoln M, Hien D, Miele GM. Substance abuse treatment entry, retention, and outcome in women: a review of the literature. Drug Alcohol Depend. 2007;86:1-21.

40. Laudet AB, Morgen $K$, White WL. The role of social supports, spirituality, religiousness, life meaning and affiliation with 12-step fellowships in quality of life satisfaction among individuals in recovery from alcohol and drug problems. Alcohol Treat Q. 2006;24:33-73.

41. Harris M, Fallot RD. Designing trauma-informed addictions services. New Dir Ment Health Serv. 2001;89:57-73.

42. Tracy EM, Johnson PJ. Personal social networks of women with co-occurring substance use and mental disorders. J Soc Work Practice Addict. 2007;7(1/2): 69-90.

43. Gonzalez-Guarda RM, McCabe BE, Vermeesch AL, Cianelli R, Florom-Smith $A L$, Peragalo N. Cultural phenomena and the syndemic factor: substance abuse, violence, HIV and depression among Hispanic women. Ann Anthropol Pract. 2012;36(2):212-31.

44. Najavits LM. Seeking Safety: An implementation guide. In: Rubin A, Springer DW, editors. The clinician's guide to evidence-based practice. New Jersey: John Wiley; 2009.

45. Centers for Disease Control and Prevention: Welcome to project RESPECT http://www.effectiveinterventions.org/en/HighlmpactPrevention/ Interventions/RESPECT.aspx (n.d). Accessed 10 Apr 2017.

46. Kamb ML, Fishbein M, Douglas JM, Rhodes F, Rogers J, Bolan G, et al. Efficacy of risk-reduction counseling to prevent human immunodeficiency virus and sexually transmitted diseases: A randomized controlled trial. JAMA 1998;280:1161-67.

47. American Psychiatric Association. Diagnostic and statistical manual of mental disorders. 5th ed. Arlington: American Psychiatric Association; 2013.

48. World Health Organization Quality of Life Group. The World Health Organization Quality of Life Assessment (WHOQOL): development and general psychometric properties. Soc Sci Med. 1998;46:1569-85.
49. Noerholm V, Groenvold M, Watt T, Bjorner JB, Rasmussen NA, Bech P. Quality of life in the Danish general population-normative data and validity of WHOQOL-BREF using Rasch and item response theory models. Qual Life Res. 2004;13:531-40.

50. Hawthorne G, Herrman H, Murphy B. Interpreting the WHOQOL-BREF: Preliminary population norms and effect sizes. Social Indicators Res. 2006;77: 37-59.

51. Litman GK, Stapleton J, Oppenheim AN, Peleg M. An instrument for measuring coping behaviours in hospitalized alcoholics: Implications for relapse prevention treatment. British J Addict. 1983;78:269-76.

52. Najavits LM. Seeking Safety: A new psychotherapy for posttraumatic stress disorder and substance abuse. In: Ouimette P, Brown P, editors. Trauma and substance abuse: Causes, consequences and treatment of comorbid disorders. Washington: American Psychological Association; 2002.

53. Najavits LM, Weiss RD, Liese BS. Group cognitive behavioral therapy for women with PTSD and substance use disorder. J Subst Abuse Treat. 1996; 13:13-22.

54. Schneider R, Burnette ML, Ilgen MA, Timko C. Prevalence and correlates of intimate partner violence victimization among men and women entering substance use disorder treatment. Violence Vict. 2009:24(6):744-56.

55. Najavits LM, Weiss RD, Shaw SR. The link between substance abuse and posttraumatic stress disorder in women. A research review. Am J Addict. 1997;6(4):273-83.

56. Ford J, Cloitre M. Best practices in psychotherapy for children and adolescents. In: Courtois C, Ford JD, editors. Treating complex trauma stress disorders. New York: The Guilford Press; 2009.

57. Robles RR, Reyes JC, Colón HM, Sahai H, Marrero CA, Matos TD, et al. Effects of combined counseling and case management to reduce HIV risk behaviors among Hispanic drug injectors in Puerto Rico: A randomized controlled study. J Subst Abuse Treat. 2004;27(2):145-52.

58. Center for Substance Abuse Treatment. Enhancing motivation for change in substance abuse treatment. Treatment Improvement Protocol (TIP) Series, No. 35. HHS Publication No. (SMA) 13-4212. Rockville: Substance Abuse and Mental Health Services Administration; 1999

59. DiClemente CC. Addiction and change: How addictions develop and addicted people recover. New York: The Guilford Press; 2003.

60. DiClemente C. Stages of change and addiction: Clinician's manual. Minnesota: Hazelden; 2004

61. IBM Corp. Released 2012. IBM SPSS Statistics for Windows, Version 20.0. Armonk, NY: IBM Corp.

62. Faul F, Erdfelder E, Lang AG, Buchner A. G*Power 3: A flexible statistical power analysis program for the social, behavioral, and biomedical sciences. Behav Res Methods. 2007;39:175-91.

63. Ryan RM, Lynch MF, Vansteenkist M, Deci EL. Motivation and autonomy in counseling, psychotherapy, and behavior change: a look at theory and practice. Couns Psychol. 2011:39(2):193-260.

64. Martin DJ, Garske JP, Davies MK. Relation of therapeutic alliance with outcome and other variables: A meta-analytic review. J Consult Clin Psychol. 2000;68:438-50

65. Horvath AO, Symonds BD. Relation between working alliance and outcome in psychotherapy: A meta-analysis. J Couns Psychol. 1991;38(2):139-49.

66. Ritsner M, Gibel A, Ratner Y. Determinants of changes in perceived quality of life in the course of schizophrenia. Qual Life Res. 2006;15:515.

\section{Submit your next manuscript to BioMed Central and we will help you at every step:}

- We accept pre-submission inquiries

- Our selector tool helps you to find the most relevant journal

- We provide round the clock customer support

- Convenient online submission

- Thorough peer review

- Inclusion in PubMed and all major indexing services

- Maximum visibility for your research

Submit your manuscript at www.biomedcentral.com/submit 